\title{
GUT REDOX CONDITIONS IN HERBIVOROUS LEPIDOPTERAN LARVAE
}

\author{
HEIDI M. APPEL ${ }^{1,2}$ and MICHAEL M. MARTIN \\ Department of Biology \\ University of Michigan \\ Ann Arbor, Michigan 48109-1048
}

(Received March 19, 1990; accepted June 14, 1990)

\begin{abstract}
Large interspecific differences in redox potential exist among herbivorous lepidopteran larvae. Reducing conditions occur in the midguts of Manduca sexta (Sphingidae) and Polia latex (Noctuidae), whereas oxidizing conditions prevail in the midguts of Lymantria dispar (Lymantriidae), Danaus plexippus (Danaidae), and Papilio glaucus (Papilionidae). The epithelium of the posterior midgut of $M$. sexta fed a diet containing bismuth subnitrate accumulates bismuth sulfide, suggesting that sulfide might be one of the reducing agents responsible for the maintenance of reducing conditions in this species. We propose that the effects of plant allelochemicals in insect herbivores will be strongly affected by gut redox conditions and that the regulation of gut redox conditions is an important adaptation of insect herbivores to the chemical defenses of plants. The redox state of the gut is yet another insect trait that must be included in the analysis of plant-insect interactions.

Key Words-Plant-insect interactions, redox, reduction potential, digestion, Lepidoptera, Danaus plexippus, Lymantria dispar, Manduca sexta, Papilio glaucus, Polia latex, Danaidae, Lymantriidae, Sphingidae, Papilionidae, Noctuidae.
\end{abstract}

\section{INTRODUCTION}

The redox conditions that prevail in an insect's gut can have a major impact on the digestion, metabolism, and assimilation of ingested nutrients. Highly reducing conditions (negative redox potentials) in the midguts of tineid moths (Water-

\footnotetext{
${ }^{1}$ To whom correspondence should be addressed.

${ }^{2}$ Present address: Pesticide Research Laboratory, Pennsylvania State University, University Park, Pennsylvania 16802.
} 
house, 1952b), dermestid beetles (Waterhouse, 1952c), and bird lice (Waterhouse, 1953) facilitate the digestion of keratin, the major protein of fur and feathers, which is highly resistant to digestion by most animals. Under reducing conditions the disulfide bonds that stabilize keratin are cleved, resulting in the liberation of polypeptide subunits that are readily degraded by insect digestive proteases. Reducing conditions are also commonly encountered in portions of the gut that house large populations of metabolically active microorganisms. Negative redox potentials have been reported in the hindguts of termites (Veivers et al., 1980; Bignell, 1984), roaches (Day and Waterhouse, 1953; Bignell, 1984), and scarab beetles (Bayon, 1980), where symbiontmediated fermentative digestion of cellulose occurs.

Gut redox conditions are also likely to mediate the impact of many classes of ingested allelochemicals on herbivorous insects. For example, the redox state of the alimentary tract is likely to determine whether ingested phenols remain in the reduced state or are oxidized to quinones, which are generally more reactive and more toxic substances than phenols. Thus, gut redox conditions are a potential adaptive mechanism by which an insect herbivore might minimize the adverse effects of ingesting the defensive chemicals present in its food plant. Prior to this study, there had been only one measurement of gut redox potential in an herbivorous insect. Bignell (1984) reported oxidizing conditions throughout the gut of Locusta migratoria. In the present study we have assessed the redox conditions in the alimentary tracts of larvae of five species of herbivorous Lepidoptera: the tobacco hornworm, Manduca sexta (Sphingidae); the cutworm Polia latex (Noctuidae); the gypsy moth, Lymantria dispar (Lymantriidae); the common monarch butterfly, Danaus plexippus (Danaidae); and the black swallowtail, Papilio glaucus (Papilionidae). In reporting and discussing our results, we have borrowed heavily from approaches developed by investigators studying the redox properties of soils.

\section{METHODS AND MATERIALS}

Oxidation-Reduction Potentials. A redox reaction is one in which there is a transfer of electrons, with or without the accompanying transfer of protons (reaction 1):

$$
\text { oxidized form }+n \mathrm{H}^{+}+n e^{-}=\text {reduced form }
$$

Consequently, whether a redox couple exists primarily in its oxidized or reduced form depends upon the availability of both protons and electrons in the system. Proton availability in a system is a function of its acid-base status. Electron availability is a function of the tendencies of the various chemical species pres- 
ent to lose electrons (and act as reducing agents) or gain electrons (and act as oxidizing agents). In a system in which proton activity and electron availability are high, reduction is favored; if proton activity and electron availability are low, oxidation is favored. If electron availability is held constant, oxidation is more favored under alkaline conditions than under acidic conditions.

The assessment of the redox conditions in an insect's gut requires a measurement of both acid-base status and electron availability. The acid-base status of the gut can, of course, be determined by a simple $\mathrm{pH}$ measurement. However, the measurement of electron availability in a complex aqueous mixture is more problematic. The standard approach has been to determine the redox potential by measuring the emf of a platinum electrode inserted into the gut and to add to the observed potential the potential difference between the reference electrode and the standard hydrogen electrode. Although redox potentials measured in this way routinely are called "standard reduction potentials" and designated by the symbol " $E_{h}$," which implies that they are equilibrium redox potentials, they are actually mixed potentials that are the resultants of all of the redox couples present in the system, most of which are not at equilibrium. The contribution of each redox couple present in the mixture is an unknown function of its concentration and its reversibility. Such mixed potentials are, therefore, only rough measures of electron availability.

In describing the redox conditions in insect guts, we have used terms developed by soil scientists to characterize the redox conditions of soils (Lindsay, 1979; Bohn et al., 1985; Bartlett, 1986). Electron availability, or "pe," is derived from the Nernst equation, and at $25^{\circ} \mathrm{C}$, is defined as:

$$
\text { pe }=E_{h} / 59.2
$$

where $E_{h}$ is the observed standard reduction potential in millivolts. Just as $\mathrm{pH}$ expresses the negative log of proton activity, pe expresses the negative log of electron activity. On either the $\mathrm{pH}$ or pe scales, zero is the standard state, and a unit of $\mathrm{pH}$ or pe is equivalent to $2.3 \mathrm{RT}$ joules of free energy per mole of protons or electrons, respectively. A low pe system has a surplus of electrons and, therefore, a high tendency to lose electrons and become more oxidized: A high pe system has a deficiency of electrons and a high tendency to gain electrons and become more reduced.

To characterize the redox status of a complex aqueous system, Lindsay (1979) has suggested using the sum of $\mathrm{pH}$ and pe as a convenient single term expression that accords equal weight to acid-base status and electron availability. He has defined pe $+\mathrm{pH}$ as the "redox parameter." By taking the logarithm of the expression for the equilibrium constant of a generalized redox half-reaction, such as reaction 1 , in which the activities of the oxidized and reduced 
species are equal, and substituting $\mathrm{pH}$ and pe for their defined equivalents, it follows that

$$
\mathrm{pe}+\mathrm{pH}=(1 / n) \log K
$$

Thus, for any given system at equilibrium, which is probably not actually the case for either soil samples or insect gut contents, pe and $\mathrm{pH}$ should change in a compensatory manner such that $\mathrm{pe}+\mathrm{pH}$ remains constant. In an aqueous system, in which the maximum oxidizing and reducing capacities are set by the water-oxygen and hydrogen-proton couples, respectively, pe $+\mathrm{pH}$ can range from a high value of 20.78 (highly oxidizing conditions) to a low value of 0 (highly reducing conditions).

Insects. Fifth-instar Manduca sexta were reared from eggs (Carolina Biological Supply) on an artificial diet (Bio-Serv \#9783) in a growth chamber at $25^{\circ} \mathrm{C}$ with a $16: 8$ light-dark photoperiod. Sixth-instar Lymantria dispar were reared from sterilized egg masses of the New Jersey-OTIS strain supplied by the USDA-ARS (APHIS, Otis AFB, Massachusetts) on artificial diet prepared according to ODell and Rollinson (1966), but lacking casein, in a growth chamber at $25^{\circ} \mathrm{C}$ with a 16:8 light-dark photoperiod. Fifth-instar Papilio glaucus were obtained from a lab culture (J.M. Scriber, Michigan State University) reared on excised foliage of tulip tree (Liriodendron tulipifera). Final instars of Polia latex and Danaus plexippus were collected from black walnut (Juglans nigra) and common milkweed (Asclepias syrica) foliage, respectively, in Centre County, Pennsylvania, and were fed excised foliage of their host until measurements of gut $\mathrm{pH}$ and $E_{h}$ were conducted.

Gut $p H, E_{\mathrm{h}}$, and pe. Three to five larvae of each species were immobilized on ice or by exposure to diethyl ether, and the gut was exposed by a ventral longitudinal incision. The integument was folded back and secured away from the gut using insect pins, and hemolymph was blotted from the integument and gut surfaces. The preparation of a larval gut required less than a minute. If dissection resulted in puncture of the gut wall, or if the gut was not full, larvae were discarded. In $M$. sexta, the shortness of the foregut precluded the accurate measurement of foregut $\mathrm{pH}$ and $E_{h}$ in all but one larva.

A longitudinal profile of gut redox potential was made using a 0.02 in. platinum electrode (Microlectrodes MI-800) and a silver-silver chloride microreference electrode (Microelectrodes MI-401) connected to a Metrohm/Brinkmann (model 103) or an Accumet (model 291) millivolt and $\mathrm{pH}$ meter. Potential measurements were made in the foregut, anterior midgut, medial midgut, posterior midgut, and hindgut. Redox potentials generally stabilized at each location within $10 \mathrm{sec}$, such that measurements on an individual larva were completed within a minute. The observed redox potentials $\left(E_{\text {obs }}\right)$ were converted to standard redox potentials $\left(E_{h}\right)$ by adding $200 \mathrm{mV}$, which is the poten- 
tial difference between the silver-silver chloride and hydrogen reference electrodes. Calculation of pe was from $E_{h}$, using the equation pe $=E_{h} / 59.2$ (Lindsay, 1979). Following the measurement of redox potential, a longitudinal profile of gut $\mathrm{pH}$ was made using a micro-needle $\mathrm{pH}$ electrode (Microelectrodes MI-408c) and a silver-silver chloride reference electrode (Microelectrodes MI401). $\mathrm{pH}$ values generally stabilized at each location of the gut within a minute, such that all measurements on an individual larva were completed within $5 \mathrm{~min}$. In $P$. glaucus and $D$. plexippus, there was some regurgitation of midgut fluid into the foregut in some animals, which compromised the accuracy of the measurements of foregut $\mathrm{pH}$ and $E_{h}$.

Mean values of $\mathrm{pH}, E_{h}$, pe, and $\mathrm{pe}+\mathrm{pH}$ were compared by ANOVA. Significant pairwise differences were determined by LSD analysis. When variances were not equal, treatment means were compared by the Kruskal-Wallis test, and the significance of pairwise differences was determined by the median test with alpha set at 0.01 to adjust for multiple comparisons.

Test for Sulfide in Midgut. M. sexta and $L$. dispar larvae, reared from eggs on artificial diets, were switched early in the fourth instar to a portion of the same artificial diet that had been amended by the addition of bismuth subnitrate (10\% dry weight). After $24 \mathrm{hr}$, three larvae of each species were immobilized and the gut exposed as described above. The presence of sulfide ions in the gut contents or gut epithelium was indicated by a black precipitate of bismuth sulfide.

\section{RESULTS AND DISCUSSION}

Previous Reports of Redox Conditions in Insect Guts. We have calculated pe and pe $+\mathrm{pH}$ at various gut locations for all insect species for which we could find measurements of $\mathrm{pH}$ and $E_{h}$ in the literature (Table 1). In most studies of gut redox conditions in insects, the results are reported as a range, not as a mean. In Table 1, we have reported the range of reported $E_{h}$ values and have calculated values for pe and pe $+\mathrm{pH}$ based on midrange values. Midrange values for pe and pe $+\mathrm{pH}$ in insects range from $-4.4-5.1$ and 2.8-11.6, respectively. To provide a measure of the most extreme reducing conditions encountered in insect guts, we also have calculated the lowest values for pe and pe $+\mathrm{pH}$ observed in those species that possess gut regions with high electron availabilities.

High electron availability (pe $<-3.0$ ) is characteristic of the hindguts of termites and the midguts of the bird lice $C$. columbae and $E$. stramineus, the dermestid beetles, and the webbing clothes moth $T$. bisselliella. Of the species listed in Table 1, the conditions most conducive to reduction (pe $+\mathrm{pH}<4.5$ ) 


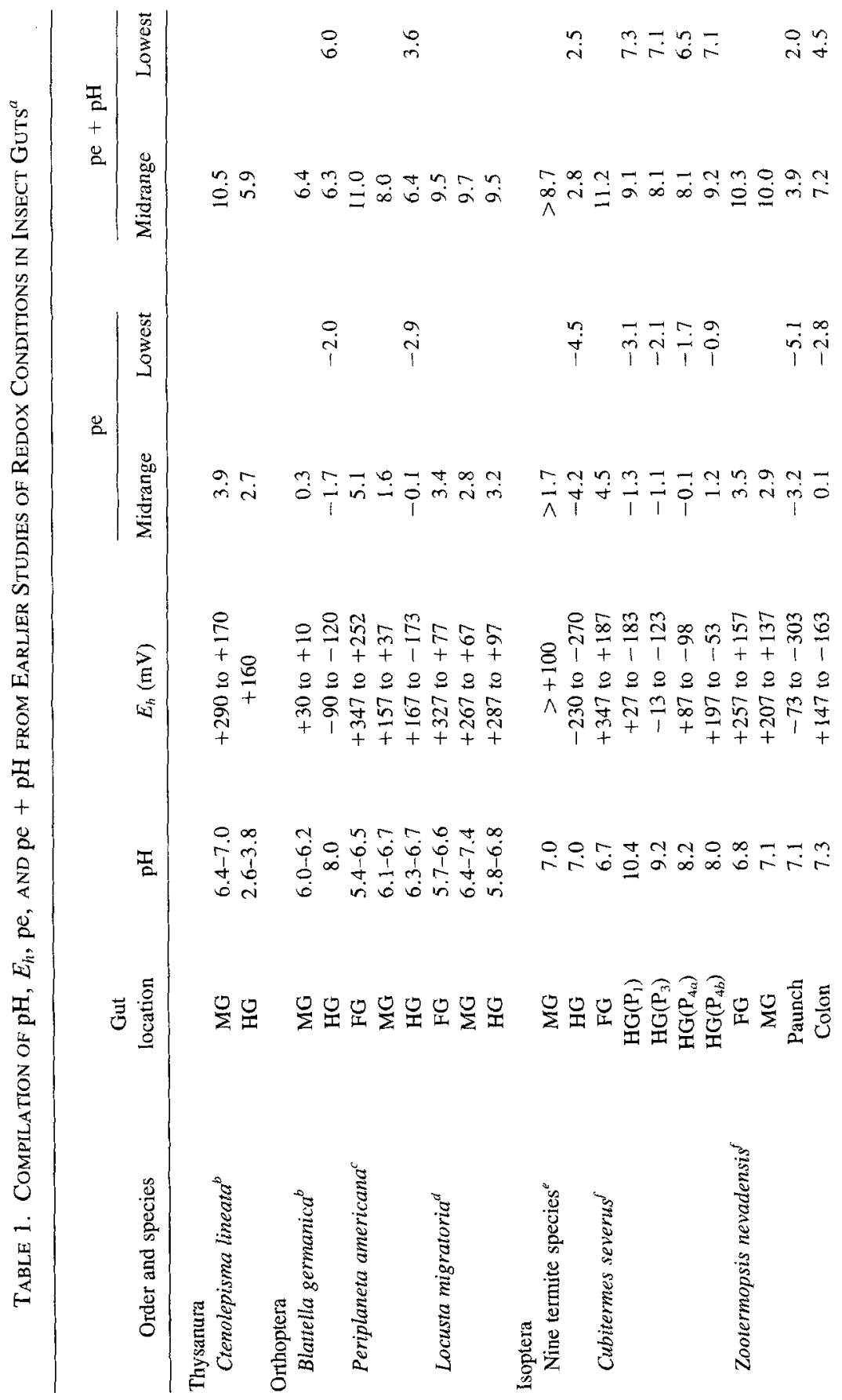




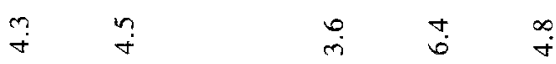

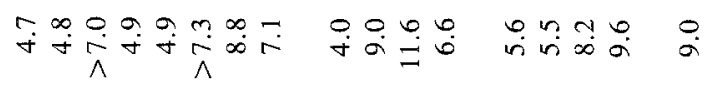

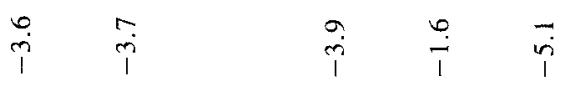

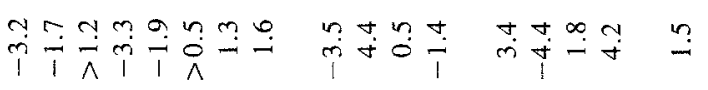

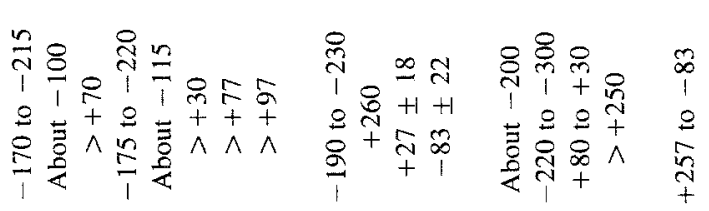

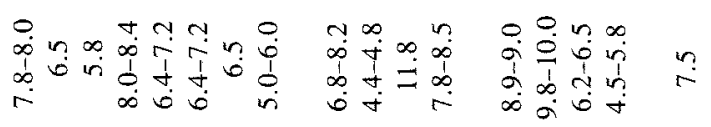

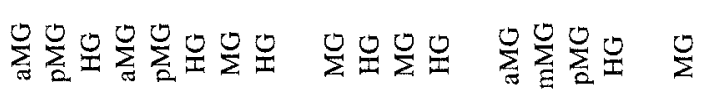

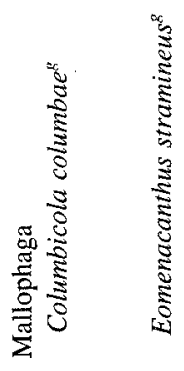

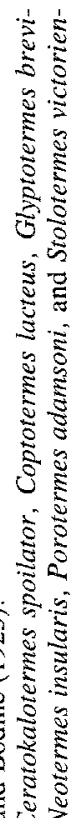

$\begin{array}{ll}6 & 0 \\ 2 & 5\end{array}$

$\approx$ is

焉造竞 空造

宓兽志

焉焉焉

घ융

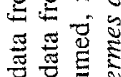

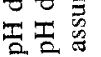

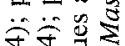

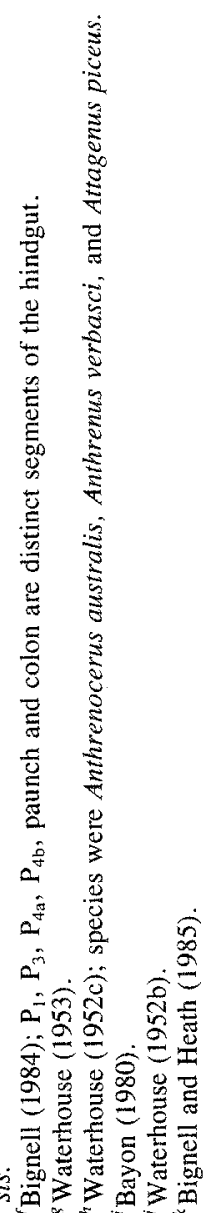


occur in the hindguts of termites and the midguts of dermestid beetles. For comparison, a flooded soil containing decomposable organic matter, with a value of pe + pH below 4.5 , would be classified as a highly anaerobic soil and might be expected to accumulate methane (Rowell, 1988). Methanogenesis is a process that is known to occur in the hindguts of many termite species (Breznak, 1984). Somewhat less extreme reducing conditions ( $\mathrm{pe}+\mathrm{pH}=4.5-7.0$ ) occur in the hindguts of the silverfish $C$. lineata, the two roach species, the soilfeeding termite $C$. severus, the rhinocerus beetle $O$. nasicornis, and in the midguts of the German cockroach $B$. germanica, the two species of bird lice, and the webbing clothes moth. For comparison, a waterlogged organic soil with a value of pe $+\mathrm{pH}$ between 4.5 and 7.0 would be classified as a reducing soil and might be expected to accumulate sulfide (Rowell, 1988). Sulfide appears to be one of the reducing agents responsible for the maintenance of high electron availability in the midgut of the webbing clothes moth (Waterhouse, 1952a; Yoshimura et al., 1988).

Redox Conditions in Gut Fluids of Herbivorous Caterpillars. Reducing conditions exist in the midguts of $M$. sexta and $P$. latex (Table 2). As in $T$. bisselliella, the reducing conditions in the midguts of $M$. sexta and $P$. latex reflect the presence of high electron availabilities (negative values of pe), which compensate for low proton availabilities (high values of $\mathrm{pH}$ ). In all three of these lepidopteran species, the lowest proton availability (highest $\mathrm{pH}$ ), the highest electron availability (most negative pe), and the most reducing conditions (lowest values of pe $+\mathrm{pH}$ ) occur in the anterior and medial portions of the midgut (Table 2). Although the conditions in the midguts of $M$. sexta and $P$. latex are reducing, they are somewhat less so than those in the midguts of the webbing clothes moth and the three dermestid beetles and than those in the hindguts of nine termite species (Table 1). However, the midguts of these two herbivorous caterpillars are as reducing as the midguts of the bird lice $C$. columbae and $E$. stramineus, the hindguts of the cockroach $B$. germanica, the scarab beetle $O$. nasicornis, and the hindguts of two termite species. The redox conditions that exist in the midguts of $M$. sexta and $P$. latex are comparable to those of a waterlogged organic soil; that is, reducing but not highly anaerobic (Rowell, 1988).

Although the midguts of $M$. sexta and $P$. latex are strongly reducing, the redox conditions that exist elsewhere in the gut are weakly oxidizing or intermediate between oxidizing and reducing (Table 3 ). Values for $E_{h}$ are uniformly positive in both the foreguts and hindguts, and values for pe and pe $+\mathrm{pH}$ fall in the ranges 2.1-2.9 and 8.6-8.7 in the foregut and 1.5-4.2 and 8.9-9.6 in the hindgut. For comparison, soil samples with values of pe and pe $+\mathrm{pH}$ comparable to those observed in the foreguts and hindguts of the larvae of these two lepidopteran species are transitional between anaerobic and aerobic conditions (Rowell, 1988). 
Table 2. $\mathrm{pH}, E_{h}$, pe and pe $+\mathrm{pH}$ of Anterior, Medial, and Posterior Midguts OF Five SPECIES OF LEPIDOPTERAN LARVAE

\begin{tabular}{|c|c|c|c|c|}
\hline $\begin{array}{l}\text { Species }(N) \text { and } \\
\text { midgut location }\end{array}$ & $\mathrm{pH}$ & $E_{h}$ & pe & $\mathrm{pe}+\mathrm{pH}$ \\
\hline \multicolumn{5}{|l|}{ Manduca sexta (5) } \\
\hline Anterior & $8.0(0.46)^{a}$ & $-131(66.6)^{a . b}$ & $-2.2(1.13)^{a . b}$ & $5.8(1.58)^{a}$ \\
\hline Medial & $9.3(1.33)^{b}$ & $-188(26.1)^{a}$ & $-3.1(0.44)^{a}$ & $6.1(0.81)^{a}$ \\
\hline Posterior & $8.2(0.66)^{a}$ & $-88(96.8)^{b}$ & $-1.5(1.63)^{b}$ & $6.8(1.38)^{a}$ \\
\hline $\operatorname{LSD}(0.05,12)$ & 0.9 & 78 & -1.3 & 1.5 \\
\hline \multicolumn{5}{|l|}{ Polia latex (4) } \\
\hline Anterior & $7.8(0.68)^{a}$ & $-85(62.1)^{a . b}$ & $-1.4(1.05)^{a . b}$ & $6.4(0.77)^{a}$ \\
\hline Medial & $8.8(0.15)^{b}$ & $-132(51.1)^{a}$ & $-2.2(0.86)^{a}$ & $6.5(0.90)^{a}$ \\
\hline Posterior & $8.3(0.76)^{a . b}$ & $-55(36.0)^{b}$ & $-0.9(0.61)^{b}$ & $7.4(0.70)^{a}$ \\
\hline $\operatorname{LSD}(0.05,9)$ & 0.8 & 66 & 1.1 & 1.0 \\
\hline \multicolumn{5}{|l|}{ Lymantria dispar (5) } \\
\hline Anterior & $8.2(0.38)^{a}$ & $+238(45.1)^{a}$ & $4.0(0.76)^{a}$ & $12.2(0.70)^{a}$ \\
\hline Medial & $8.2(0.27)^{a}$ & $+214(36.1)^{a}$ & $3.6(0.61)^{a}$ & $11.8(0.76)^{a}$ \\
\hline Posterior & $7.9(0.39)^{a}$ & $+218(35.7)^{a}$ & $3.7(0.61)^{a}$ & $11.6(0.35)^{a}$ \\
\hline $\operatorname{LSD}(0.05,12)$ & 0.4 & 44 & 0.7 & 1.1 \\
\hline \multicolumn{5}{|l|}{ Danaus plexippus (3) } \\
\hline Anterior & $8.6(0.49)^{a}$ & $+77(9.1)^{a}$ & $1.3(0.15)^{a}$ & $9.9(0.35)^{a}$ \\
\hline Medial & $8.5(0.15)^{a}$ & $+54(4.9)^{b}$ & $0.9(0.01)^{b}$ & $9.4(0.11)^{b}$ \\
\hline Posterior & $8.1(0.31)^{a}$ & $+91(8.6)^{c}$ & $1.5(0.14)^{c}$ & $9.6(0.40)^{a . t}$ \\
\hline $\operatorname{LSD}(0.05,6)$ & 0.6 & 12 & 0.2 & 0.5 \\
\hline \multicolumn{5}{|l|}{ Papilio glaucus (3) } \\
\hline Anterior & $10.1(0.50)^{a}$ & $+17(58.6)^{\alpha}$ & $0.3(0.99)^{a}$ & $10.4(0.98)^{a}$ \\
\hline Medial & $10.1(0.47)^{a}$ & $+48(7.4)^{a}$ & $0.8(0.12)^{a}$ & $11.0(0.42)^{a}$ \\
\hline Posterior & $9.8(0.74)^{a}$ & $+57(28.0)^{a}$ & $1.0(0.47)^{a}$ & $10.8(0.29)^{a}$ \\
\hline $\operatorname{LSD}(0.05,6)$ & 0.9 & 179 & 1.0 & 1.0 \\
\hline
\end{tabular}

${ }^{a}$ Values are means with standard deviations given in parentheses. In comparisons of different locations in the same species, values followed by the same letter are not significantly different at $P$ $<0.05$.

In contrast to $M$. sexta and $P$. latex, which have reducing midguts and mildly oxidizing foreguts and hindguts, $L$. dispar, D. plexippus, and $P$. glaucus larvae have guts in which oxidizing conditions prevail throughout (Tables 2 and 3 ). The average values of pe and pe $+\mathrm{pH}$ in the midguts of these species are in the ranges $0.7-3.8$ and 9.5-11.9, respectively. Soils with these values for pe and pe $+\mathrm{pH}$ would be classified as aerobic soils (Rowell, 1988).

As the midgut is the primary site of digestion and assimilation in larval Lepidoptera, the large interspecific differences in midgut redox conditions reported here reflect significant differences in the chemical environment in which digestion and assimilation occur. 
Table 3. pH, $E_{h}$, pe, and pe + pH of Foreguts, Midguts, and Hindguts of Five SPECIES OF LePIDOPTERAN LARVAE ${ }^{a}$

\begin{tabular}{|c|c|c|c|c|}
\hline $\begin{array}{l}\text { Species and gut } \\
\text { location }(\mathrm{N})\end{array}$ & $\mathrm{pH}$ & $E_{h}$ & pe & $\mathrm{pe}+\mathrm{pH}$ \\
\hline \multicolumn{5}{|l|}{ Manduca sexta } \\
\hline Foregut (1) & 5.7 & +172 & 2.9 & 8.6 \\
\hline Midgut (5) & $8.5(0.61)^{a, 1}$ & $-136(51.0)^{a .1}$ & $-2.3(0.86)^{a .1}$ & $6.2(0.99)^{a .1}$ \\
\hline Hindgut (5) & $7.4(0.79)^{b .1}$ & $+86(48.0)^{b .1}$ & $1.5(0.81)^{b .1}$ & $8.9(0.85)^{b .1}$ \\
\hline $\operatorname{LSD}(0.05,8)$ & 0.8 & 58 & 1.0 & 1.1 \\
\hline \multicolumn{5}{|l|}{ Polia latex } \\
\hline Foregut (4) & $6.6(1.27)^{a .1}$ & $+123(147.2)^{a .1}$ & $2.1(2.49)^{a .1}$ & $8.7(2.21)^{a . b .1}$ \\
\hline Midgut (4) & $8.3(0.39)^{h .1}$ & $-91(43.6)^{b .1}$ & $-1.6(0.71)^{b .1}$ & $6.7(0.63)^{a .1}$ \\
\hline Hindgut (4) & $7.3(0.92)^{a . b .1}$ & $+99(60.2)^{a .1 .3}$ & $1.7(1.04)^{a .1 .3}$ & $8.9(1.82)^{b .1 .2}$ \\
\hline $\operatorname{LSD}(0.05,9)$ & 1.2 & 123 & 2.1 & 2.2 \\
\hline \multicolumn{5}{|l|}{ Lymantria dispar } \\
\hline Foregut (5) & $6.4(0.41)^{a .1}$ & $+236(45.6)^{a .1}$ & $4.0(0.77)^{a .1}$ & $10.5(0.83)^{a .1}$ \\
\hline Midgut (5) & $8.1(0.23)^{h .1}$ & $+223(36.4)^{a .2}$ & $3.8(0.61)^{4.2}$ & $11.9(0.56)^{h .2}$ \\
\hline Hindgut (5) & $7.1(0.43)^{c .1}$ & $+204(36.6)^{a .2 .3}$ & $3.5(0.62)^{a .2 .3}$ & $10.5(0.51)^{a .2}$ \\
\hline $\operatorname{LSD}(0.05,12)$ & 0.4 & 45 & 0.8 & 0.8 \\
\hline \multicolumn{5}{|l|}{ Danaus plexippus } \\
\hline Foregut (3) & $7.5(0.96)^{4 . h .1 .2}$ & $+127(73.5)^{a .1}$ & $2.1(1.25)^{a .1}$ & $9.6(0.42)^{a .1}$ \\
\hline Midgut (3) & $8.4(0.06)^{a .1}$ & $+74(3.5)^{a .3}$ & $1.1(0.06)^{a .3}$ & $9.5(0.10)^{a .3}$ \\
\hline Hindgut (3) & $7.2(0.52)^{b .1}$ & $+114(14.8)^{a .1}$ & $1.8(0.25)^{a .1}$ & $9.0(0.73)^{a .1 .2}$ \\
\hline $\operatorname{LSD}(0.05,6)$ & 1.0 & 69 & 1.2 & 0.7 \\
\hline \multicolumn{5}{|l|}{ Papilio glaucus } \\
\hline Foregut (3) & $8.9(1.42)^{a . b .2}$ & $+122(87.9)^{a . b .1}$ & $2.1(1.51)^{a . b .1}$ & $11.0(0.26)^{a .1}$ \\
\hline Midgut (3) & $10.0(0.57)^{a .2}$ & $+41(26.0)^{a .3}$ & $0.7(0.40)^{a .3}$ & $10.7(0.40)^{\alpha .2 .3}$ \\
\hline Hindgut (3) & $7.6(0.40)^{h .1}$ & $+133(18.9)^{b .1 .3}$ & $2.2(0.32)^{b, 1.3}$ & $9.8(0.10)^{h .1 .2}$ \\
\hline $\operatorname{LSD}(0.05,6)$ & 1.4 & 86 & 1.4 & 0.5 \\
\hline
\end{tabular}

${ }^{a}$ Values are means with standard deviations given in parentheses. Midgut values are the averages of the anterior, medial, and posterior midgut values reported in Table 2 . In comparisons of different gut locations within a species, values followed by the same letter are not significantly different $P<0.05$. In comparisons of the same gut locations between different species, values followed by the same number are not significantly different at $P<0.01$.

Absorption of Bismuth Salts by Midgut Epithelium of M. sexta. When $M$. sexta larvae consumed artificial diet that contained bismuth subnitrate, the posterior midgut epithelium became dark brown (Figure 1), presumably because of the accumulation of bismuth sulfide in the cavities of the goblet cells. A similar accumulation of insoluble metal sulfides in the goblet cells of the midgut epithelium has been reported for the larvae of $T$. bisselliella fed a diet containing soluble metal salts (Waterhouse, 1952a). The accumulation of bismuth sulfide in the midgut epithelium of $M$. sexta and $T$. bisselliella larvae fed diets amended with bismuth subnitrate suggests that in both species sulfide may be 


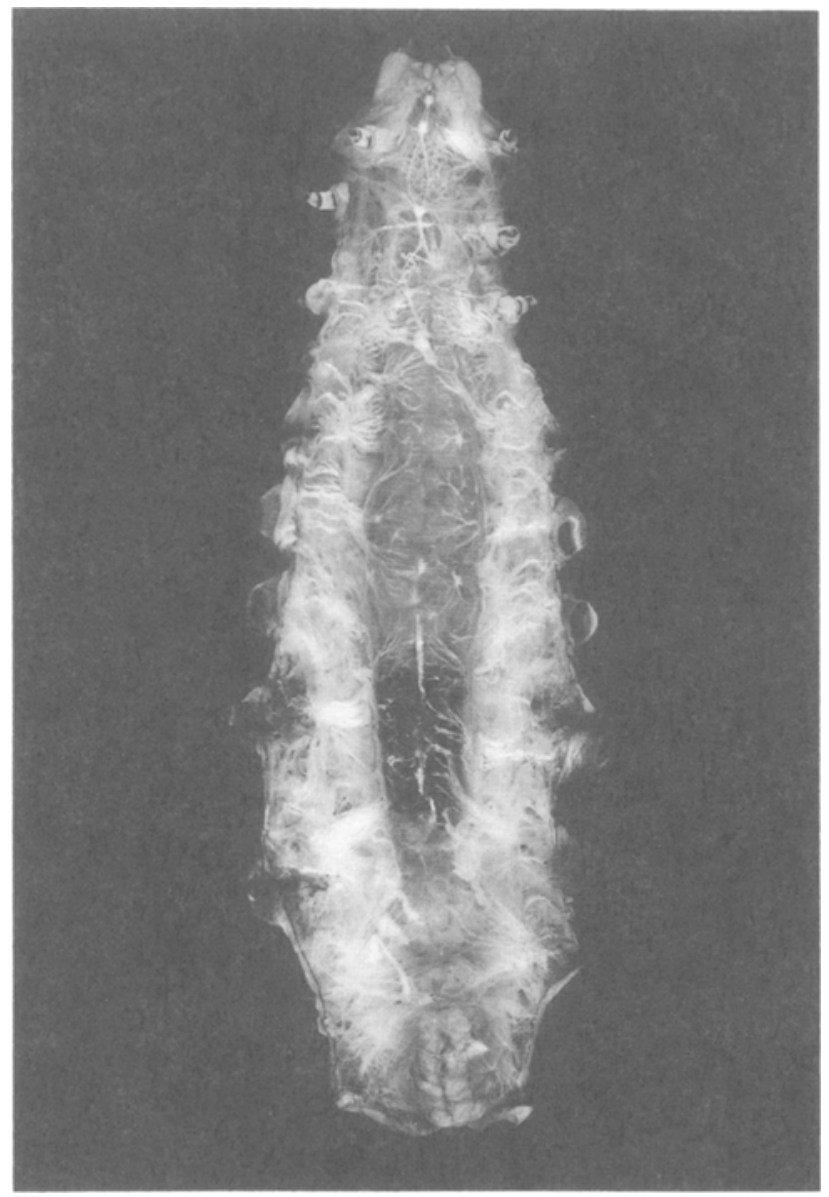

FIG. 1. Ventral view of the alimentary tract of a fourth-instar $M$. sexta larva that had been feeding on an artificial diet that included $10 \%$ bismuth subnitrate. The anterior of the larva is at the top of the photograph. The darkened region is the posterior third of the midgut. The dark substance, presumably bismuth sulfide, is in the midgut epithelium, not in the lumen contents.

one of the reducing agents responsible for the maintenance of reducing conditions. In $T$. bisselliella the sulfide is generated from cysteine by the action of L-cysteine lyase (Yoshimura et al., 1988).

No accumulation of bismuth sulfide was evident in the midgut epithelium of $L$. dispar larvae fed a diet amended with bismuth subnitrate.

Significance of Midgut Redox Conditions to Lepidopteran Herbivores. The redox state of the gut is likely to mediate the effects of many plant allelochem- 
icals on insect herbivores. The impact of ingested phenols is likely to be especially dependent upon the redox conditions encountered in the gut, since quinones, which are oxidation products of phenols, are generally more reactive and more toxic than their phenolic precursors. Quinones can form covalent bonds with nucleophilic groups present in a variety of nutritionally important compounds (Leatham et al., 1980; Hurrell et al., 1982). The oxidation of foliar phenols, mediated by ingested foliar phenoloxidases, has been shown to reduce the efficiency of utilization of dietary amino acids and proteins in larvae of the tomato fruitworm, Heliothis zea (Lepidoptera, Noctuidae) (Felton et al., 1989). In addition, the toxic effects of plant phenols may depend upon the formation of highly reactive superoxide anion radicals during phenol oxidation. These reactive intermediates have been shown to inactivate enzymes, disrupt membranes, and damage DNA in mammals (Smith, 1985). Oxygen radicals, produced during the metabolism of phenols, may be responsible for the gut lesions observed in some insect herbivores maintained on diets rich in tannins (Bernays et al., 1980; Steinly and Berenbaum, 1985). Thus, both antinutritional and toxic effects of plant phenols may be strongly influenced by the redox conditions of the gut.

On the other hand, the oxidation of ingested phenols can have beneficial consequences for insect herbivores when the adverse effects on growth and fecundity are offset by the beneficial effects of reducing susceptibility to infection by microbial pathogens. The oxidation products of ingested phenols afford protection against the infection of $H$. zea by the nuclear polyhedrosis virus, HzSNPV (Felton and Duffey, 1990). Similarly, ingested phenols have been shown to protect the gypsy moth, $L$. dispar, against infection by the nuclear polyhedrosis virus GMNPV (Keating et al., 1989), although it has not yet been demonstrated that oxidized phenols are involved. Thus, it is possible that for one herbivore it would be advantageous to prevent phenol oxidation by the maintenance of reducing conditions in the midgut, whereas in another it would be advantageous to promote phenol oxidation by the maintenance of oxidizing conditions throughout the gut.

Tree-feeding caterpillars are more likely to encounter higher concentrations of tannins and other polyphenols than forb-feeding caterpillars. We were interested in determining whether there was a relationship between the growth form of the larval food plant and the redox conditions maintained in the midgut. We observed reducing conditions in one tree-feeder $(P$. latex $)$ and one forbfeeder (M. sexta) and oxidizing conditions in two tree-feeders ( $L$. dispar and $P$. glaucus) and one forb-feeder (D. plexippus). Thus, even this limited survey reveals that factors other than host plant growth form must account for the dichotomy between those Lepidoptera with oxidizing and those with reducing midguts.

We do not know yet whether ingested phenols undergo significant oxidation in the midguts of $L$. dispar, D. plexippus, and $P$. glaucus. Nor do we know 
whether the conditions in the midguts of $M$. sexta and $P$. latex are sufficiently reducing to prevent the oxidation of ingested foliar phenols or to reduce ingested foliar quinones. Definitive resolution of those questions can be achieved only by determining the chemical fates of phenols of known structure that have been introduced into midgut fluids. On the basis of the findings reported in this paper, however, we feel justified in drawing the following conclusions: (1) the conditions in the midguts of $M$. sexta and $P$. latex are less conducive to the oxidation of ingested foliar phenols than the conditions in the midguts of $L$. dispar, $D$. plexippus, and $P$. glaucus; (2) the extent of oxidation of some foliar constituents will be greater in the midguts of $L$. dispar, $D$. plexippus, and $P$. glaucus than in the midguts of $M$. sexta and $P$. latex; and (3) some foliar constituents that are oxidized in the midguts of $L$. dispar, $D$. plexippus, and $P$. glaucus will not be oxidized in the midguts of $M$. sexta and $P$. latex. On the basis of these conclusions, we propose that the effects of plant allelochemicals on insect herbivores will be affected by gut redox conditions and that the regulation of gut redox conditions is an important adaptation of insect herbivores to the chemical defenses of plants. The redox state of the gut is yet another insect trait that must be included in the analysis of plant-insect interactions.

Acknowledgments - We thank the National Science Foundation for grants BSR-8421268 and BSR-8904043 to M.M. Martin and BSR-8605106 to J.C. Schultz, and the U.S. Department of Agriculture for grant 88-37251-4046 to J.C. Schultz, which supported this work. We thank J.M. Scriber for $P$. glaucus larvae, J.C. Schultz for $L$. dispar and $P$. latex larvae, and D.N. Karowe for help in statistical analyses. We also thank an anonymous referee for useful suggestions for revision.

\section{REFERENCES}

BARTLETT, R.J. 1986. Soil redox behavior, pp. 179-207, in D.L. Sparks (ed.). Soil Physical Chemistry. CRC Press, Boca Raton, Florida.

BAYON, C. 1980. Volatile fatty acids and methane production in relation to anaerobic carbohydrate fermentation in Oryctes nasicornis larvae (Coleoptera: Scarabaeidae). J. Insect Physiol. 26:819-828.

Bernays, E.A., Chamberlain, D., and MCCarthy, P. 1980. The differential effects of ingested tannic acid on different species of Acridoidea. Entomol. Exp. Appl. 28:158-166.

Bignell, D.E. 1981. Nutrition and digestion, pp. 57-86, in W.J. Bell and K.G. Adiyodi (eds.). The American Cockroach. Chapman and Hall, London.

BigNelL, D.E. 1984. Direct potentiometric determination of redox potentials of the gut contents in the termites Zootermopsis nevadensis and Cubitermes severus and in three other arthropods. J. Insect Physiol. 30:169-174.

BigneLL, D.E., and HEATH, L.A.F. 1985. Electropositive redox state of the fifth-instar larval gut of Apis mellifera. J. Apic. Res. 24:211-213.

Bodine, J.H. 1925. Physiology of the Orthoptera. Hydrogen ion concentration of the blood and alimentary tract of certain Orthoptera (grasshoppers). Biol. Bull. 48:79-82.

Bohn, H.L., MCNeal, B.L., and O'Connor, G.A. 1985. Soil Chemistry, 2nd ed. John Wiley \& Sons, New York.

BREZNAK, J.A. 1984. Biochemical aspects of symbiosis between termites and their intestinal sym- 
bionts, pp. 173-203, in J.M. Anderson, A.D.M. Rayner and D.W.H. Walton (eds.). Invertebrate-Microbial Interactions. Cambridge University Press, Cambridge, England.

DAY, M.F., and WaterhousE, D.F. 1953. The mechanism of digestion, pp. 311-330, in K.D. Roeder (ed.). Insect Physiology. John Wiley \& Sons, New York.

FELTON, G.W., and DuFFEY, S.S. 1990. Inactivation of baculovirus by quinones formed in insectdamaged plant tissues. J. Chem. Ecol. 16:1221-1236.

Felton, G.W., Donato, K., Del Vecchio, R.J., and Duffey, S.S. 1989. Activation of plant foliar oxidases by insect feeding reduces nutritive quality of foliage for noctuid herbivores. $J$. Chem. Ecol. 15:2667-2694.

Hurrell, R.F., FinOt, P.A., and CuQ, J.L. 1982. Protein-polyphenol reactions. 1. Nutritional and metabolic consequences of the reaction between oxidized caffeic acid and the lysine residues of casein. Br. J. Nutr. 47:191-211.

Keating, S.T., McCarthy, W.J., and Yendol, W.G. 1989. Gypsy moth (Lymantria dispar) larval susceptibility to a baculovirus affected by selected nutrients, hydrogen ions $(\mathrm{pH})$, and plant allelochemicals in artificial diets. J. Invert. Pathol. 54:165-174.

Leatham, G.F., King, V., and Stahmann, M.A. 1980. In vitro protein polymerization by quinones or free radicals generated by plant or fungal oxidative enzymes. Phytopathology 70:11341140.

Lindsay, W.L. 1979. Chemical Equilibria in Soils. John Wiley \& Sons, New York.

ODELL, T.M., and Rollinson, W. 1966. A technique for rearing the gypsy moth on an artificial diet. J. Econ. Entomol. 59:741-742.

Rowel. D.L. 1988. Flooded and poorly drained soils, pp. 899-926, in A. Wild (ed.). Russell's Soil Conditions and Plant Growth, 11 th ed. Longman Scientific and Technical, Essex, England

SMITH, M.T. 1985. Quinones as mutagens, carcinogens, and anticancer agents: Introduction and overview. J. Toxicol. Environ. Health 16:665-672.

SRIVASTAVA, U.S, and SRIVASTAVA, P.D. 1956. On the hydrogen ion concentration in the alimentary canal of certain orthopteroid insects. Beitr. Entomol. 6:493-498.

Steinly, B.A., and Berenbaum, M. 1985. Histopathological effects of tannins on the midgut epithelium of Papilio polyxenes and Pieris brassicae. Entomol. Exp. Appl. 39:3-9.

VEIVERS, P.C., O'BRIEN, R.W., and SLAYTOR, M. 1980. The redox state of the gut of termites. $J$. Insect Physiol. 26:75-77.

Waterhouse, D.F. 1952a. Studies on the digestion of wool by insects. IV. Absorption and elimination of metals by lepidopterous larvae, with special reference to the clothes moth, Tineola bisselliella. Austr. J. Sci. Res. 5B:143-168.

WATERHOUSE, D.F. 1952b. Studies on the digestion of wool by insects. VI. The pH and oxidationreduction potential of the alimentary canal of the clothes moth (Tineola bisselliella) (Humm.) Austr. J. Sci. Res. 5B:178-188.

Waterhouse, D.F. 1952c. Studies on the digestion of wool by insects. VII. Some features of digestion in three species of dermistid larvae and a comparison with Tineola larvae. Austr. $J$. Sci. Res. 5B:444-459.

Waterhouse, D.F. 1953. Studies on the digestion of wool by insects. IX. Some features of digestion by chewing lice (Mallophaga) from bird and mammalian hosts. Austr. J. Sci. Res. 6B:257275.

Yoshimura, T., Tabata, H., Nishio, M., Ide, E., Yamaoko, R., and Hayashiya, K. 1988. LCysteine lyase of the webbing clothes moth, Tineola bisselliella. Insect Biochem. 18:771777 . 